\title{
The Ritual Music of Wana People
}

\author{
Giorgio Scalici \\ Univeristy of Rome “La Sapienza”, Piazzale Aldo Moro 5, Rome 00185, Italy. \\ E-mail: giorgio_scalici@yahoo.it
}

\begin{abstract}
Very ancient practice, shamanism is usually found in the nomadic or seminomadic cultures. Given the dependence on the hunt for these populations, one of the fundamental roles of the shaman was to mediate between man and nature, especially between men and the lords of the animals that make possible the success of a hunting expedition. Shamanism has, however, shown a great ability to adapt to historical events, managing to keep up to us maintaining its uniqueness. Threatened by the arrival of progress and the world religions, has been able to respond actively and to influence the Western culture, as evidenced by the New Age movement and the presence of shamans in many movies, books and videogames. These fascinating, complex and archaic belief has always attracted the interest of the West, evidenced by historical, literary and academic publications, and it seems that still shamanism still has not exhausted what has to offer the world. In this article I am going to describe which the situation of the Wana religion to the present day is and which the rituals of this culture are. The Wana have two shamanic rituals the momagu and the molawo -that face the disease with music, showing us the central role of music in the ritual life of this community, affirming - once again- the importance of music not just to Wana but also to humankind, and its relationship with the hidden world.
\end{abstract}

Keywords: Wana, shaman, ritual, music, trance.

\section{INTRODUCTION}

The Wana are a small cultural group who live inside the Morowali forest, since the arrival of Indian settlers (Alvard, 2000: 59) or perhaps even earlier times.

That has led them to get in deep touch with the Hindu culture. This contact is witnessed by the presence in their culture of many Hindu terms and notions: the same word wana means forest in Sanskrit. There were also contacts with the Muslim culture. Wana believe that Muslims are their brothers, and this conception of brotherhood reflects a cordial relationship between the two communities. Unfortunately, the relationship with the Christian community is more complicated. The Christians desire to convert and their sense of superiority -often the converted Wana do not have a good opinion of the not-yet-converted - have led to some frictions that, luckily, have never erupted into violence. 


\section{MATERIALS AND METHODS}

\section{The Reserve}

The Morowali forest is located in the mid-East of the Sulawesi Island, and stretches from the Kolonodale Gulf through the hinterland to the Bongka Tojo bay. On November 1986, the Ministry of Forestry of Indonesia designated Morowali nature reserve. The reserve hosts the $12 \%$ of the world's bird species, and has many rivers (Lhadji, 1999: 238). On one hand living inside a natural reserve is protecting Wana from mass tourism and the exploitation of the reserve, on the other hand this has created problems between Wana and the Indonesian government. Due to the slash and burn technique on which is based the Wana agriculture the government considers them as "environmental vandals" (Lhadji, 1999: 240), although, in 2000, Alvard has demonstrated that the Wana agricultural system is not a problem for the ecosystem of the forest (Alvard, 2000: 438). After several clashes the Wana have coined the motto "tare pamarentah, tare agama, tare kampung"1 (Lahadji, 2008: 23).

\section{The Life in the Jungle}

According to the World Wildlife Fund Report, in 1980, the number of Wana was around 5000 people (Lhadji, 1999: 238). The Wana live in villages of different sizes. The ones I got to visit were inhabited by about sixty people, such as Marisa, or just over twenty - like the Kajupoli settlement.

In their gardens Wana cultivate papaya, bamboo, tapioca and rice. Unfortunately the climatic change has decreased the rice crop, leading to the demise of the harvest ritual and increasing the trade with the villages outside the reserve. To gain the money to buy petrol, rice, clothes, food, etc. the Wana collect dammar gum, rattan, coconut and cocoa that they sell to Chinese companies. Near the border of the reserve there are some oil palm plantations that are having a big impact on Wana life and culture.

\section{Religion}

The base of Wana religion is Pue, the creator god. The religion currently can seem a monotheistic system but there are various elements that suggest a gradual shift from an early stage in which were worshiped the lords of the animals. Between the present monotheism and the passed veneration of the lords of the animals there was an intermediate stage with two main deities; Pue Ri Arantana -god of the undergrounddispenser of rewards and punishments, and Pue Lamoa -god of the sky and lightningwhich can cause illness and pain to mankind. These steps are not clearly marked and it is easy to run into difficult to interpret data. Om Suma once told me: "There is a Pue who lives underground. He is very benevolent and if we want to succeed we have to give him something but if we misbehave - he will punish us". This statement testifies a strong resistance of the belief in Pue Ri Arantana, which has partial characteristics of the disappeared Pue Lamoa.

Among Wana I had the opportunity to see a shamanic tradition that, despite the

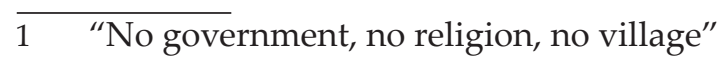


interference of the contemporary world - such as piece work in the plantations of oil palm, the strong presence of the monotheistic religions and the interest of young people towards modernity - still seem to be strong and esteemed.

\section{The Shamanism}

The shamans are considered an asset of the community, as well as ritual instruments. Whenever the shaman Apa Ingus came to the Marisa village he had requested curative services. He never refused, and his reward was very poor, only 10000 rupees. I witnessed similar scenes also in Tarongo, where Indo Pino cured the child of our host. These examples show the trust in these operators of the sacred, the strong kasintuwu (sense of community) which permeates the entire culture of Wana.

This faith in the shaman skills seems strengthened not only by the success of their rites, but the existence of a mythical archetype: Dungola. He is the son-along with his fifteen siblings- of Santoto and Delemntu, the first couple of humankind. According to the myth, Dungola was so powerful that his rituals lasted three nights in a row and, besides being the mythical archetype of the shaman; he encloses the musician and entertainer, a triple role that immediately puts emphasis on the link between shamanism, music and celebration. We must keep in mind that the momagu is also one of the few occasions to celebrate, as also attested by Atkinson: "Apart from a mabolong ${ }^{2}$, weddings, funerals, and four annual festivals farming, it is rare for coresidents of a swidden settlement to congregate as a group" (Atkinson, 1989: 7). In the end, the momagu is an excellent opportunity to socialize and get drunk accompanied by the incessant music of gongs and drum.

The ability to travel between human and spirits world, and his familiarity with the latter puts the shaman in the same status of his walia (spirits). This fellowship allows the shaman to possess various powers, he can: walk in the sky, hypnotize a person, talk to the dead, predict the future and become invisible (jampu). Most of the powers of the shaman are available only during the momagu. The ritual implements a return to the mythical time - when men and spirits lived together and even men possessed great powers. The shaman is the living link with mythical past, with his mystical journey he dramatizes the ancient ability to travel from earth to heaven and back. Shamans are poised between the human world and the hidden world. Their confidence and alliance with the spirits puts them on a line between qualitatively different times, the mythical time when everything was full of power and present time in which men live in poverty.

\section{Past Research on Wana}

There are very few researches that focus on Wana and I can divide them into three main groups. The first group is composed of the research about the agriculture and ecosystem inside Morowali, like the researches of Alvard (2000) and Operation Drake (1981). The most important works are those of Jabar Lahadji, ex director of the association Yayasan Sahabat Morowali (friends of Morowali).

2 Momagu and mabolong are the same ritual. 
In the second group there are the anthropological and religious researches, as the book written by the Dutch missionary Kruyt - De to Wana op Oost-Celebes (1930), who in the twenties has lived for two months with the Wana, and the book - The art and politics of Wana seamanship (1989) - and the articles (1983, 1987, 1992, 2003) of Jane Monnig Atkinson, who, between the 1974 and 1976, lived in the forest and made an admirable analysis of the momagu. Finally, there are the documentaries of Journet e Nougarol $(2005,2007,2011)$, which cover many aspects of Wana life, as the relationship with the Christians and the life of the reserve.

\section{Methodology}

Was the work of Atkinson to push me to do my research among the Wana, reading her works I discovered the presence of a ritual music which, however, was not analyzed. So I decided to document and analyze that music in order to discover the role of it in Wana culture and religion.

I spent five months inside the reserve putting into practice the basics of participant observation.

That allowed me a deeper immersion into the Wana culture, and a deeper understanding of it. During my presence among the Wana I tried to be involved in their life - I was hosted by shamans or village chiefs - and to observe their lives to understand the Wana mindset, to get as close to an emic perspective as possible.

In addition to the observation I enriched my research with interviews. These were more close to an open dialogue, in which information flowed back and forth between me and the Wana. I also noticed that a list of questions can become tedious to the interviewee that may get bored and decide to terminate the interview. I also tried to write life histories. This would have required a lot more time than five months but I was able to write short biographies that have allowed me to understand how it has changed the life in the reserve, what is the role of the shaman in the community and to acquiring more information on shaman apprenticeship. I did a qualitative research to understand why people do what they do. Often it crossed disciplinary boundaries and strayed from a single focused subject, for this I had to use my anthropology, religion and ethnomusicological knowledge.

During the research I took handwritten notes because the shortage of electricity within the reserve prevented the massive use of the audio recorder, and also because the audio recorder would intimidate the Wana. I preferred to use the audio recorder for the myths because I did not wanted to interrupt the speaker, and I wanted to have the opportunity to listen again the myths to translate them. To give a testimony as complete as possible of the rituals I have also used a camera and a camcorder. With these I have also documented the construction of all Wana music instruments to preserve the memory of this work of craftsmanship, both for us and for the Wana.

Once I came back to Italy I began a long process of bibliographic research in order to better understand what I had found and to compare my findings with the old researches on Wana and other similar research for a cross-cultural comparison to come to new insights and I came to new results which initially had not thought of. 


\section{Problems}

During my research I faced many problems that there are common to many scholars. The most obvious was the language. No Wana speak English and not everybody speaks Indonesian. I had to study Indonesian at the University Sebelas Maret of Surakarta and once in Morowali I had to start learning the Wana language. Another problem has been finding electricity. Inside the reserve there are some villages that possess an electrical generator that is used to see movies. Usually a member of the village buys the petrol and allows the whole village to watch the movie. I could have access to electricity for irregular periods and this forced me use my electrical equipment with parsimony. For this reason I did not have the opportunity to record an entire ritual, but only parts of it.

Another problem has been moving inside the jungle. Apart from the obvious difficulties and dangers -steep and slippery paths, thorns and leeches, ford the rivers- the main problem was walk for several hours, even six or more, carrying all the equipment and materials that I needed. It was also difficult and stressful record the rituals without any help; I had to take pictures, record the music, shoot video, ask for explanations and -especially-observe all at the same time. I wish you all could do your research with a team as it should be, also because the biggest problem to do research so far from home is the loneliness.

\section{What I Found}

Wana have three main rituals, two shamanic and one funeral. The funeral one is called kayori: after the death of a Wana the community gathers and two groups of people describe -singing for two nights- the path to the suruga (paradise) to the dead soul, only at the end of the song the dead will definitely enter the suruga and will be separated from the world of living.

It would require an essay in its own to talk about this ritual but here will talk of the two shamanic rituals, the momagu, which has also been studied by Atkinson with the name of mabolong, and the molawo that had never been studied before.

\section{The Rituals in the Time}

To do this, I will compare the results of the research of Kruyt, in 1928 in the Tarongo area, of Atkinson, in 1978 in the northern part of the reserve and finally mine, in 2011 in the villages of Marisa, Kajupoli and Tarongo.

During his short stay among Wana - only two months - Kruyt came into contact with various utterances of shamanic power that he distinguished in order of power and importance. "The lowest level is walia mangepe" (Atkinson 1989, p. 207), in this domestic ritual the shaman detects and extracts invisible objects from the patient's body sucking or pulling it with a pompolonzu (ritual cloth), the ritual is accompanied by one or more doa (invocation). "Next in Kruyt's shamanic order is walia mantende" (Atkinson, 1989: 207), this ritual consists just in a long song with which the shaman requires Pue Lamoa to remove the hooks that afflict the sick. The ritual is known by the same name by Atkinson, while in the area which I worked this ritual is called molawo. "Then follows walia moganda" (Atkinson, 1989: 207), called mabolong in the area studied by Atkinson and momagu in mine. 
Finally: "At the top of Kruyt's hierarchy are to walia mamparada woto ntongku. [...] This ritual takes place in the salia, a great ritual performed once a year to promote the health and well-being of a community" (Atkinson, 1989: 207). None of the three of us had the opportunity to observe this ritual.

\section{Momagu}

The shamanic rituals are required in case someone feels afflicted by some inner ill and not in the event of normal diseases. When a member of a family becomes ill due to causes attributable to an inner ill, this family strives to make sure that the momagu will be run as early as possible. The preparation does not take much time - it is possible to arrange it even within a single day.

The family needs to get large quantities of rice, tobacco, alcohol, betel and everything that can be requested by the walia (spirits) or by the bystanders. The key issue is the presence of -at least- two tau walia (shamans. Literally man spirit). In case that a shaman would be in danger, the presence of a second shaman who can rush to his aid is providential. There are many people who get together to attend the ceremony, on every occasion that I documented the house where the ceremony took place was filled. "People go to mabolong to enjoy themselves, to receive treatment, and to demonstrate kasintuwu, "mutual support", an important social value [...] Although the mabolong is the most popular events of healing, its popularity comes from the repute it involves much more than healing" (Atkinson, 1989: 26). The momagu is also a festive occasion to share an important moment for the community, "illness is only one excuse for a mabolong. Anticipation of misfortune, successful recoveries from previous illness, marriages, farming festivals, visits by prominent shamans, as well as a general desire to party, are all reason to hold a mabolong" (Atkinson, 1989: 6).

During the preparations the offerings to the spirits are placed on a lango (tray). These offers usually consist of amounts of alcohol, betel, money, toothpaste, eggs, clothes and anything else that may please the walia. Copious quantities of alcohol, tobacco and rice are available to all present that will use them throughout the night. It is recommended to ensure the abundance of quantities because "if guests do not enjoy, the ritual will not be good."

\subsection{Dance and Music}

It's the sound of ritual instruments -gongs and drums- to mark the beginning of the momagu. The music draws walia while is the light to keep them away. For this reason, the ritual must be strictly officiated at night -without artificial lights- and the ceremony will end before the sunrise. Once audience arrives the musicians begin to play. Atkinson reports a rhythm called topo with which heralds the beginning of the ritual (Atkinson, 1989: 27), in the area which I studied topo there is a version -for a single musician- of the music played in the past with the tetebua (bamboo zither) during the momagu.

Other difference between our researches seems to be the presence of songs, performed by the players, "the drum provides the main rhythm, called a "song" (linga), the words to which the audience knows. The themes of these drum songs range from courtship to 
spirit encounters, from headhunting days of old to contemporary poverty" (Atkinson, 1989: 27). In addition, Atkinson does not seem to mention different paces while the Wana distinguish three different rhythms - or speeds - which give the time to the shamanic dance: the motaro. It means "to jump up and down" while women dance is called salonde "literally, something beautiful" (Atkinson, 1989: 94). The salonde it can have a courtship purpose and it is a much more complex and fluid dance, especially in the use of arms.

The aim of the shamanic dance is to favorite the concentration. With the same aim is used the pompolonzu; a piece of cloth, often made from a T-shirt, that the shaman shakes or with which he covers his face to promote its concentration. Unfortunately, while the motaro seems to maintain its strength and popularity, I have ascertained a shortage of female shamans. This is due to shyness, common in Wana girls that refrain from dancing salonde. The dances are accompanied by the drum and gongs. At the head of the ritual instruments is one of the two players of the drum, who decides the rhythm according to his impressions of how it is going the ritual. The three rhythms as are: malenyilenyi (slow: 4/4, 140 BPM), tumba biasa (medium: 4/4, 150 BPM ) and pakoba manoto (fast: 4/4, $240 \mathrm{BPM}$ ). There is a fourth rhythm for the salonde called ngaya (185 BPM). While other rhythms were characterized by extreme synchrony and precision, this rhythm seems to make of the interlocking its main feature. The same speed -about 185 BPM- seems to give a sense of instability. The music evokes the fluid motion of salonde. This dance -with its soft movements of the arms and body and its loving purposes- needs a more flexible music, which gives more freedom of expression, creativity and movement to the dancer.

There is a continuous alternation of these rhythms, thus generates moments of calm and tension. Moreover, with the increase of speed, the sound of the gongs, which propagates well beyond the duration of the rhythmic cycle, starts to amalgamate with the sound produced by the succeeding beat, these exacerbate the tension and encourage trance. The ritual music is played for hours and hours, becoming a veritable mantra that creeps into the ears of the listeners and helps the shamans to dissociate themselves from the surrounding environment.

\subsection{Structure}

The momagu does not have a fixed course since it is "performed-centered, governed less by liturgy and more by the action and inclinations of individual practitioners" (Atkinson, 1989: 14) and "no overall structure appears to groom the occasion" (Atkinson, 1989: 19).

Although organized by a single family, the momagu is a community ritual: there are always present a variety of people who will ask to the shamans to cure themselves or their children. The organization of the ritual is responsibility of one family, but the entire community will benefit. There is a clear affirmation of the kasintuwu.

So the ritual consists of more shamanic journeys, one for each patient. Between a cure and the other can pass several minutes, during this time there may be silence, dance or just chatting. The presence of several shamans leads to an ever-changing ritual healing. "A mabolong is a circus with more than one ring" (Atkinson, 1989: 246). 
Despite the interweaving of disparate actions, we can try to divide the momagu in fix parts: evocation of spirits, patient care, travel in the sky, negotiate to Pue, return of the soul to its rightful owner. Of utmost importance is the search for the soul of the sick and negotiation with Pue; during the trance, the shaman travels between the worlds and his visions are recounted in his songs.

Once the shaman has found the soul, the catch is often dramatized; shamans nab the air, as if to recover the soul escaped, and then store it in the owner's head, putting on stage their journey as "shamanic texts are best described as dramatic dances [...] in non- literate cultures religion is always a performing art, and the sacredness of religious stories or prayers resides not in the words of the texts as they not have been transcribed or Could be but in the power invested in them through performance" (Porterfield, 1987: 726).

These trips actualize the mythic time within the boundaries of space and time of the ritual, marked by the music. The ritual is the revival of the time when the ability to travel between worlds was common knowledge and not only exclusive of shamans.

\subsection{The Chant}

Although covered by environmental noise shamanic chant is well understood by Wana than often intervene with comments about what the tau walia sees on his travels. The chant joins other ritual elements in order to restore the mythical time. With the song "symbolically, the patient is rendered contemporary of creation; lives, therefore, the initial state of fullness. You do not repair a faulty body, the patient must be born again and thus recover the amount of energy and potential which has to be a time of birth. This is made possible by the memory of the patient himself"3 (Eliade, 1957: 47). I want underline that the song the patient listens during the momagu is the same song that he heard as a child as a spectator. At an unconscious level is activated a memory that nurtures confidence in the shaman and his healing power, and it is this trust which will make possible the recovery.

Rousseau told us: "As long as you will want to consider only the sounds for the action they exert on our nerves, you do not know the true principles of music and its power over the hearts. The sound in the melody does not act solely as sounds, but as signs of our affections" (as cited in Rouget, 1980: 231).

\section{Molawo}

When the momagu has no effect and even the doctors are able to cure the disease, Wana resort to another ritual: the molawo.

Given its role as last bulwark against death, this ritual is considered very powerful and not all shamans can do it. The molawo is considered the mother of all other shamanic rituals (Atkinson, 1989: 211), Atkinson (1989) writes: “a separate set of procedures ritual was reserved for victims of Lamoa. The most elaborate of these procedures was called molawo maneo, the 'crooked' molawo" (Atkinson, 1989: 199).

The structure, scope and organization of this ritual are different - if not diametrically

3 These and other quotations from books not written in English were translated by me. 
opposed -to that of momagu. First, while in the momagu the shaman travels between the worlds and comes into contact with Pue, during the molawo is Pue Lamoa who will decide the fate of the patient.

As I wrote before, in the past Wana were not monotheists but believed in the existence of two gods: Pue Re Arantana and Pue Lamoa, god of the sky and lightning, god is much feared. In molawo, in fact, is absent any characterization festive. It is celebrated in the forest, in broad daylight and in the presence of a few people, is banned any loud noise, and there is only one shaman who will try to convince Pue Lamoa to loosen the grip on the invisible mata mpea (hooks) that tear the flesh of the sick and to transfer the ill to other objects or animals.

The absence of instrumental music and the presence of light are possible because the shamans do not need to call his spirits, but he will be negotiating with Pue Lamoa. Actually what Wana consider a song seems to me a speech monotone and rhythmic. "The invigorating effect of the song [...] is based on its ability to eventually give the affected person a vocabulary in terms of which to grasp the nature of your illness and refer it to the world [...] a song mainly aims to present a picture of the specific and concrete genuinely human suffering and therefore bearable, powerful enough to fend off the challenge of meaninglessness emotional pain provoked by the existence of a brutal, intense and incurable" (Geertz, 1973: 133-134). The ritual is divided into three distinct parts that follow one another cyclically until the end of the rite.

After the patient lay on the floor, the tau walia takes it in her hand a betel nut (fua) and two sugar canes, the betel represents the patient himself. The shaman holding canes in their hands will speak his litany, he passes the canes three times from the patient's head to his feet, and three times from feet to head demanding to Pue Lamoa to transfer the ill to the canes and betel. At the end of the whole ritual a cane will be wrapped in a cloth and placed on the roof in the direction of the sun that dies while the other will be buried in the direction of the rising sun. In the second part the shaman rubs on the body of the patient six pompolonzu, three pieces are passed from head to feet and the other three from feet to head. The pieces are rubbed over and over again but always in groups of six. At the end of the ritual he will put all the pieces on the roof of the patient's home, halfway between Pue Lamoa and the sick.

In the last part of the ritual, the shaman covers a chicken and the patient to avoid any contact between them because -during this phase- he will pass the volatile over the patient three times from head to feet and three times from feet to head. At the end of the molawo, the bird will no longer be touched or eaten. Not all shamans know the molawo chant because it is prerogative of the highest rank tau walia. They are, in fact, very rare occasions in which it is officiated. During my research, I had the opportunity to attend just to one rite. The execution of the molawo is located on the border between the spoken is sung. It consists of an initial melisma on the first vowel. Usually the melody begins with an $\mathrm{A} 3$ goes up to $\mathrm{Bb}$ and then fell straight down, syllable by syllable, to the D. Each melisma differs slightly from the others but they all tend to follow this path ascending and descending. The melisma is then followed by a spell matching of the phrase, difficult to place in the definition of spoken or sung. 
Perhaps Giannattasio in his From spoken to sung (2002) can tell us the reason for this particular execution: "A monotonic trend usually has to do with the needs of its transcendence of the word magic formulas or devotional and, more generally of prayers. [...] It can be assumed that: the flattening of the profile intonation seems somehow liberate prayer and religious discourse from emotional traits and referential quotas, giving them a solemn stillness"' (p. 1019).

Given the great structural similarity of these invocations, I decided to offer just a part of the chant in order to highlight the musical structure of this ritual.

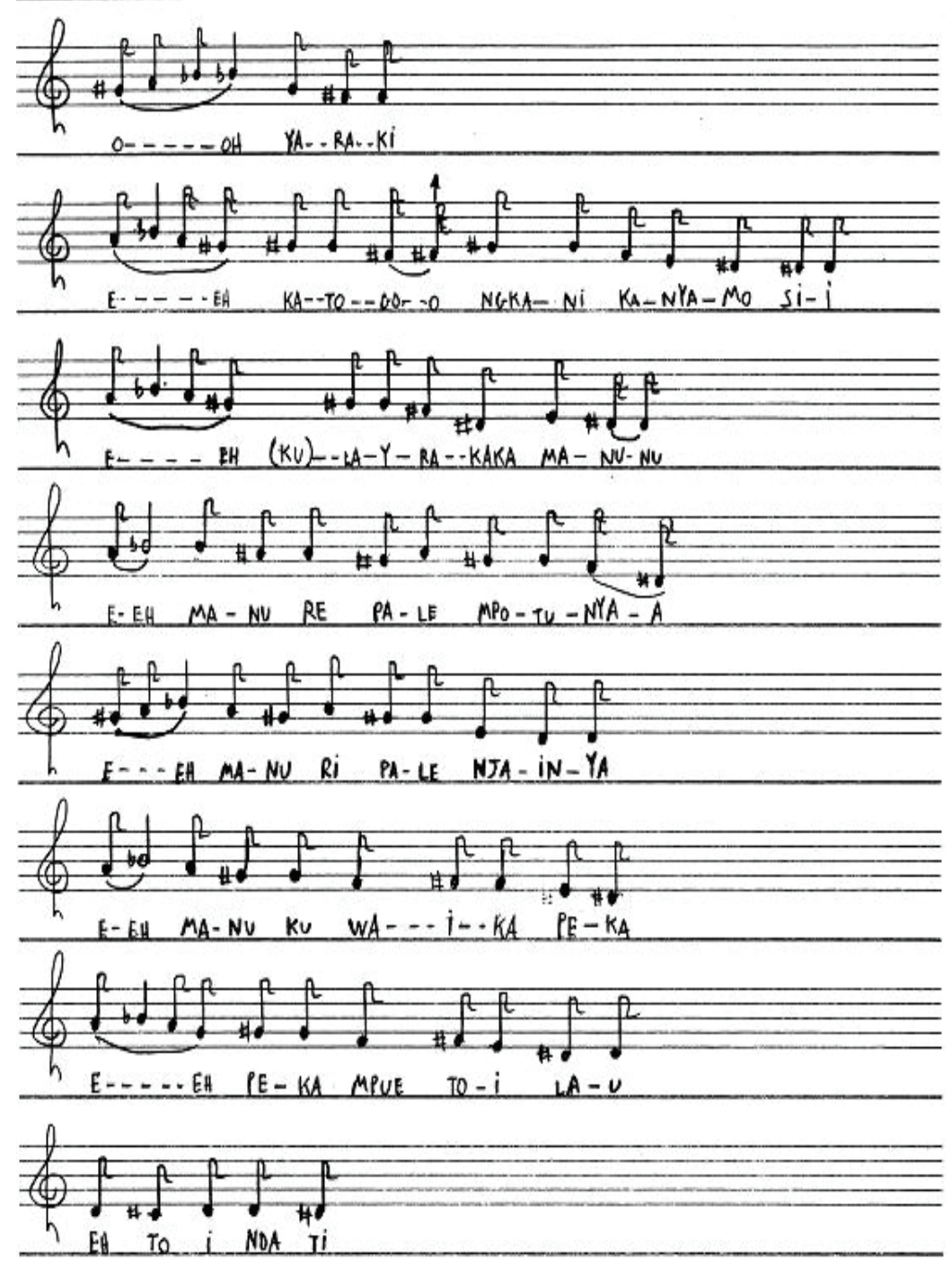

\section{CONCLUSION}

How we could see Wana consider the rituals inseparable from music, so much so that it is impossible to perform a ritual without it.

With the sound of gongs, or with a chant or with a rhythmic speech the music must be always present when they are facing a moment of crisis, like illness or death, because how Otto said (1956) “what is essential and great requires to be sung" (p. 125). During 
the rituals the music transforms the everyday time to mythical time and gives power to everything, the music is the mark of myth, is the testimony of the presence of God, for the Wana, e also for us.

This proves - once again - that music is not just a recreation but a necessity of the soul.

The Wana testimony put a small piece in the big puzzle that is the research on the link between music and sacred, and the relationship between music and trance.

This and many other experiences give to this world a diversity to admire and protect but - at the same time - give us the opportunity to discover what we all - as human beings - have in common.

As Wade Davies (2003) said: "This world deserves to exist in a different way, we can find a way to live in a truly multicultural, pluralistic world where all of the wisdom of all peoples can contribute to our collective well-being".

\section{REFERENCES}

Alvard, M. S. (2000). The Potential for Sustainable Harvests by Traditional Wana Hunters in Morowali Nature Reserve, Central Sulawesi, Indonesia. Human Organization, 59 (4), 428-440.

Atkinson, J. M. (2003). Who appears in the family album? Writing the history of Indonesia's revolutionary struggle. In R. Rosaldo (Ed.), Cultural Citizenship in Island Southeast Asia: Nation and Belonging in the Hinterlands (134-161). Berkeley, CA: University of California Press.

(1992). Shamanisms Today. Annual Review of Anthropology, 21, 307-330.

(1989). The Art and Politics of Wana Seamanship. Berkeley; CA: University of California Press.

(1988). Religion and the Wana of Sulawesi. In M. Dove (Ed.), The Real and Imagined Role of Culture in Development. Case studies from Indonesia (pp.41-61). Honolulu; HI: University of Hawaii Press.

(1987). The Effectiveness of Shamans in an Indonesian Ritual. American Anthropologist, New Series, 89 (2), 342-355.

(1983). Religions in dialogue: The construction of an Indonesian minority religion. American Ethnologist, 10 (4), 684-696.

Davis, W. (2003). Dreams from Endangered Cultures. Retrieved from TED website: http:// www.ted.com/talks/wade_davis_on_endangered_cultures.html

Eliade, M. (1957). Mythe, rêves et mystères, Paris, F: Gallimard.

Geertz, C.(1973). The Interpretation of Cultures. New York, NY: Basic Books.

Giannattasio, F. (2002). Dal parlato al cantato. In J.J. Nattiez (Ed.), Enciclopedia della musica Einaudi Vol V (pp. 1003- 1036), Torin, IT: Einaudi.

Journet, M., Nougarol, G. (2011). Indo Pino. Marseille, F: IRD audiovisuel. (2005). Gods and Satans. Paris, F: Le miroir. (2007). The Shadow. Göttingen, D: Institut für Visuelle Ethnographie (IVE).

Kruyt, A. C. (1930). De To Wana op Oost-Celebes. Jakarta, RI: Koninklijk Bataviaasch Genootschap van Kunsten en Wetenschappen.

Lahadji, J. (2008). People, Park and Partnership. Problems and Possible Solutions in the Morowali Nature Reserve. IIAS Newsletter, 46, 2-23.

Lahadji, J. (1999). Morowali Nature Reserve and the Wana People. In M. Colchester, \& C. Erni (Eds.), Indigenous Peoples and Protected Areas in South and Southeast Asia: From Principles to Practice (pp.228-249). Amsterdam, NL: Aksant Academic Publ. 
Mitchell, A. W. (1981). Operation Drake: Voyage of Discovery. London , U.K.: Severn House Publisher Limited.

Otto, W. F. (1956). Theophania. Der Geist der altgriechischen Religion, Hamburg, D: Rowohlt.

Portefield, A. (1987). Shamanism: A Psychosocial Definition. Journal of the American Academy of Religion, 55 (4), 721- 739.

Rouget, G. (1980). La musique et la trance: Esquisse d'une théorie générale des relations de la musique et de la possession. Parigi, F: Gallimard. 